\title{
Drug Abuse in Sports: An Overview
}

\section{Alka Beotra}

\section{ABSTRACT}

The use of drugs to enhance performance in sports is termed as doping and is prevalent since ancient times. In India, the trigger to setup facility for the testing of banned substances was the first positive of an Indian weight lifter in 1990 Auckland Commonwealth Games. The Indian laboratory got ISO/IEC 17025: 1999 accreditation in 2003 and WADA accreditation in 2008. It accomplished testing for the two major international games (1st Singapore Youth Olympics and 19th Commonwealth Games) in 2010 successfully. The evaluation of statistics of sample testing in India revealed the maximum number of positives in bodybuilding, athletics, kabbadi, weightlifting and powerlifting. The most prevalent group of drugs in the banned category was anabolic steroids followed by stimulants and diuretics. The implementation of highest standard of quality control is essential for the doping laboratories to ensure best laboratory practices along with the ongoing research to keep up with the advancements in detection of new substances. The sports persons also need to be more vigilant about the prevalent antidoping rules and regulations.

Keywords: Doping, Prevalence, Nutritional supplements Drug testing.

How to cite this article: Beotra A. Drug Abuse in Sports: An Overview. J Postgrad Med Edu Res 2013;47(2):94-98.

Source of support: Ministry of Youth Affairs and Sports, Government of India.

Conflict of interest: None declared

\section{INTRODUCTION}

The use of drugs to improve performance in sports is prevalent since ancient times. The use of drugs to gain an advantage over others in competition is called doping, which remains a serious issue, putting an athlete's health at risk and also threatening the integrity and reputation of sport. ${ }^{1,2}$ Doping is defined by the International Olympic Committee (IOC) as the 'use of any substance foreign to the body and taken with sole intention of increasing in unfair manner his/ her performance in competition'.

The World Anti-Doping Agency (WADA) was established in 1999 and in 2004 it redefined doping as the 'occurrence of one or more of the following antidoping rule violations mentioned in the WADA code'.

Antidoping rule violations mentioned in WADA code:

1. The presence of prohibited substance or its metabolites in an athlete's bodily specimen,

2. Use of a prohibited substance or a prohibited method,

3. Refusing or evading sample collection,

4. Violation of athlete availability for out-of-competition testing including failure to provide required whereabouts information which are declared based on reasonable rules,

5. Tampering or attempting to tamper, with any part of doping control,

6. Possession of prohibited substances and prohibited methods,

7. Trafficking in any prohibited substance or prohibited method,

8. Administration or attempted administration to a prohibited substance or prohibited method to any athlete.

\section{List of Drugs Banned in Sports by WADA}

The prohibited list of drugs devised by IOC in 1967 consisted of only stimulants, narcotics and analgesics. The number of drugs and metabolites in the banned list at that time was approximately 40 to 50, which was periodically upgraded by the IOC Medical Commission until the constitution of WADA in 1999. The updating/revision of the banned list ranged from inclusion of new group in the banned list or inclusion of new drug in the existing group. The revision may be regarding the threshold concentration of a particular drug or regarding minimum required performance limit (MRPL). ${ }^{3}$ At present, the list ${ }^{4}$ includes more than 300 drugs and metabolites which fall into the following categories of drugs:

1. Prohibited substances in sports:

- S0-Nonapproved substances

- S1-Anabolic agents

- S2-Peptide hormones, growth factors and related substances

- S3-Beta-2 agonists (except salbutamol, salmeterol and formatorol)

- S4-Hormone and metabolic modulators

- S5-Diuretics and other masking agents

- S6-Stimulants

- S7-Narcotics

- S8-Cannabinoids

- S9-Glucocorticosteroids

2. Prohibited methods in sports:

- M1-Manipulation of blood and blood components

- M2-Chemical and physical manipulation

- M3-Gene doping

3. Substances prohibited in specific sports:

- P1-Alcohol

- P2-Beta-blockers 


\section{Prohibited Substances in Sports}

The category of nonapproved substances (S0) was included in the banned list in 2011. The drugs under this category have no current approval by any governmental regulatory health authority for human therapeutic use (e.g. drugs under preclinical or clinical development or discontinued, designer drugs, substances approved only for veterinary use) are prohibited at all times. The use of anabolic agents (S1) in sports is prevalent since 1960s, but was put into the banned list in 1975. It is the most abused group out of all the categories of drugs. The anabolic agents are used clinically for the treatment of various ailments, but athletes use these drugs to increase muscle mass, protein metabolism, etc. The commonly used anabolic steroids are nandrolone, stanozolol, testosterone, etc. The peptide hormones, growth factors and related substances (S2) got prominence since last 15 years, when the erythropoietin (EPO), a hormone involved in the production of red blood cells (RBCs) was manufactured by the pharmaceutical laboratories. The clinical use of EPO was to boost the number of RBCs in anemic patients to healthy levels. But, it was misused by athletes due to the effect of increased RBCs on the oxygen carrying capacity thereby improving endurance.

The use of beta-2 agonists (S3) is banned since 1990s but lot of changes in the regulations are introduced permitting inhalation of salbutamol, formoterol and salmeterol and provision of threshold concentration for both salbutamol and formeterol to restrict higher dose of the inhalation than required for therapeutic purpose. ${ }^{5}$ With more advancement in the knowledge of the chemists assisting use of drugs, the group hormone antagonists and modulators (S4) got lot of inclusions since last few years from aromatase inhibitors in the beginning to selective estrogen receptor modulators (SERMs), antiestrogenic substances and now inclusion of agents modifying myostatin function, metabolic modulators, etc (insulins, peroxisome proliferator activated receptor, etc). The diuretics are banned since 1988 (S5) but the other masking agents (desmopressin and plasma expanders) got into the list later making the detection of the doping substances tedious for the testers.

Stimulants (S6) was the first group of drugs to be banned in sports in 1967. Since then, various developments took place in terms of detection and categorization of drugs falling in this group. The group has both specified (ephedrines) and nonspecified stimulants (amphetamines) which mean that the drugs which may be used inadvertently for the therapeutic purpose has milder sanctions compared to the nonspecified category. Further, the drugs which are used for the treatment of cough and cold, e.g. ephedrines fall into threshold category which is to be quantitated by the doping laboratories and if found above the threshold level, then only sanctions are to be imposed. The methylhexaneamine is a drug which re-emerged in the supplements and was banned for use in 2010 earlier in nonspecified category and later in the specified category. The abuse of the drug is found in both India and other parts of the world. ${ }^{6,7}$ The narcotics (S7) are used as strong pain killers in post-surgical treatment but athletes use these drugs to mask pain so as to play for longer period. Its use is more addictive than as performance enhancing, e.g. morphine, heroin and pethidine. The cannabinoids (S8) and glucocorticosteroids (S9) were earlier in the restricted category where the drugs are banned under special circumstances. Both the groups are now into main list subject to prohibition during competition. All glucocorticosteroids are prohibited when administered by oral, intravenous, intramuscular or rectal routes.

\section{Prohibited Methods in Sports}

The prohibited methods in sports involve administration of any quantity of blood or RBC products (M1). It also involves artificially enhancing the uptake, transport or delivery of oxygen. An extra-dose of RBCs, providing extra-endurance, is similar to what can be achieved with EPO- except that it is faster and less risky. Athletes can take blood from people with the same blood type, or from those with a compatible blood type. The tampering of integrity and validity of samples (M2) collected during doping control is prohibited. The tempering may involve substitution or adulteration of urine. The transfer of normal or genetically modified genes (M3) to enhance performance is also prohibited.

\section{Substances Prohibited in Specific Sports}

The use of alcohol (P1) and beta-blockers (P2) is prohibited under specific sports. The testing of alcohol is done through breath analysis and beta-blockers are tested in shooting, archery, fencing wrestling, etc.

\section{Specified Substances}

All the prohibited substances except all anabolic agents, peptide hormones, all prohibited methods and few of the stimulants fall into the category of specified substances. A specified substance is a substance which allows, under defined conditions, for a greater reduction of a 2-year sanction when an athlete tests positive for that particular substance.

The prohibited list of drugs which classifies all prohibited drugs, prohibited methods and masking agents is considered as reference document of WADA. The fight against doping continues to be based on the capability of 
the antidoping laboratories to develop and apply analytical procedures for the most effective detection of all substances and methods included in the prohibited list.

\section{Nutritional Supplements in Sports}

The sports person resort to the use of nonpharmaceutical products, especially nutritional supplements to improve performance. The correct use of nutritional supplements with proper scientific guidance may be safe, but there are some cases in which the situation is not that simple: For instance when a product contains one or more of banned substances that could lead to a positive doping result. ${ }^{8-11}$ This is the case for (a) herbal products, in which the active principles may be indicated with different names (e.g. kuchla instead of strychnine or ma huang instead of ephedrines), (b) prohormones in which the active principles, correctly indicated in the label, are metabolic precursors of endogenous steroid hormones (such as androstenedione and norandrostenedione, precursors of testosterone and nandrolone respectively), and (c) contamination of mislabeled products, in which an athlete may be unaware of the presence of a forbidden substance. In the last case the presence of illicit substance can be the result of accidental contamination or fraud. In any case, if an athlete purchases nutritional supplements from companies which offer prohibited substances in their sales catalogs, he/she runs a very big risk. Hence, it is recommended to use the certified nutritional supplements.

\section{Drug Testing in Sports}

The testing of drugs in the body fluids takes place in two different situations: For diagnosis purpose in medical field and for penalty purpose in forensic/doping field. In the medical field, the physician requests the test and the patient is both fully cooperative with the sample collection to provide the ideal sample. In the latter case the nonmedical authority requests for the sample and it may not be in the best interest of the individual to submit a valid sample. In the medical model the information obtained from the test is used to assist the physician in the care and management of the patient. In contrast, in the penalty model the results are used to impose some penalty to the individual. This fundamental difference together with legal imperatives has broad implications for the overall design and implementation of a drug testing program. To keep this objective in mind, the worldwide antidoping efforts are now better organized, harmonized and structured than before. The quality assurance program in the laboratories involved in doing testing ensures to provide the analytical results of sufficient accuracy for their intended application.

In India, National Dope Testing Laboratory (NDTL), which is one of the 33 WADA accredited laboratories in the world, is engaged in the fight against doping since last 2 decades. The antidoping program in India is strengthened year by year by means of stringent testing protocol, extensive research and education. The protocol of testing procedures involved in NDTL ${ }^{12,13}$ for the testing of samples is given in Table 1. The evaluation of drug testing statistics in the form of number of samples tested so far in the last 2 decades $(32,000)$ along with the percent positive of samples $(4.34 \%)$ shows that the most prevalent group of drug misused in sports is anabolic agents. The evaluation of percent positives in various disciplines from 2009 to 2012 shows the maximum abuse of drugs in body building (22\%), athletics and kabbadi (19\%) weightlifting (13\%) and powerlifting (6\%) (Fig. 1). As per the statistics of testing in the Indian laboratory, the percent positive of anabolic steroids is maximum followed by stimulants, diuretics (Fig. 2) and other drugs which is in conformity to the worldwide statistics as given by WADA. ${ }^{14}$ Among the anabolic steroids, the most abused drugs are stanozolol, nandrolone, methandienone and testosterone (Fig. 3). The nandrolone, stanozolol, methandienone and testosterone can be regarded as 'old' doping agents that were used extensively decades ago, and are still used to enhance performance. As per WADA statistics for the year 2011, anabolic androgenic steroids comprised $59.4 \%$ of all adverse analytical findings reported by all the accredited laboratories, out of which, maximum abused anabolic steroids were metabolites of nandrolone (7.2\%), stanozolol (8.3\%) and methandienone (4.4\%). ${ }^{14}$

Table 1: (A) Procedures for testing of urine samples, and (B) procedures for testing of blood samples

\begin{tabular}{|c|c|c|c|c|}
\hline \multicolumn{5}{|c|}{ A. Procedures for testing of urine samples: } \\
\hline $\begin{array}{ll}\text { Screening } 1 \\
\text { - } & \text { Stimulants and } \\
\text { narcotics } \\
\text { - } & \text { GC-NPD/MSD }\end{array}$ & $\begin{array}{l}\text { Screening } 3 \\
\text { - } \quad \text { Plasma volume } \\
\text { expanders } \\
\text { - } \quad \text { LC-MS/MS }\end{array}$ & $\begin{array}{l}\text { Screening } 4 \\
\text { - } \quad \text { AAS } \\
\text { - } \quad \text { GC-MSD \& } \\
\text { GC-MS/MS }\end{array}$ & $\begin{array}{l}\text { Screening } 7 \\
\text { - hCG and LH } \\
\text { - } \quad \text { ELISA }\end{array}$ & $\begin{array}{l}\text { Screening } 8 \\
\text { - Corticosteroids, beta-blockers, } \\
\text { diuretics and other drugs } \\
\text { - LC-MS/MS }\end{array}$ \\
\hline \multicolumn{5}{|c|}{ B. Procedures for testing of blood samples: } \\
\hline $\begin{array}{l}\text { Screening } 10 \\
\text { • hGH } \\
\text { - Luminometry }\end{array}$ & $\begin{array}{l}\text { Screening } 12 \\
\text { - } \quad \text { EPO and CERA } \\
\text { - } \quad \text { Electrophoresis }\end{array}$ & \multicolumn{3}{|c|}{$\begin{array}{l}\text { Screening } 13 \\
\text { - } \quad \text { Blood transfusion } \\
\text { - }\end{array}$} \\
\hline
\end{tabular}


The dope testing methods are improving with more and more advancement in the testing protocol both in terms of equipment and processing of samples. This has led to improving the detection window which in turn has facilitated more number of positives being reported worldwide. The testing of stanozolol improved ${ }^{15}$ in terms of better extraction method and more sensitive equipment (LCMSMS) which led to increased prevalence of positives. ${ }^{16}$ The statistical analysis of stanozolol positive cases by event during 2004 to 2009 shows highest percent of positives in weightlifting (34.7\%) followed by athletics (25\%), bodybuilding (18.7\%) and powerlifting (16.4\%). ${ }^{16}$ Further evaluation of data from 2010 to 2012 reveals the change in the pattern of prevalence of the drug with maximum positives in bodybuilding (28\%) followed by kabbadi (26\%), athletics (15\%) and powerlifting (11\%).

The research in antidoping laboratories aims into identifying various metabolites of drug so as to find longterm marker metabolites to extend detection window of

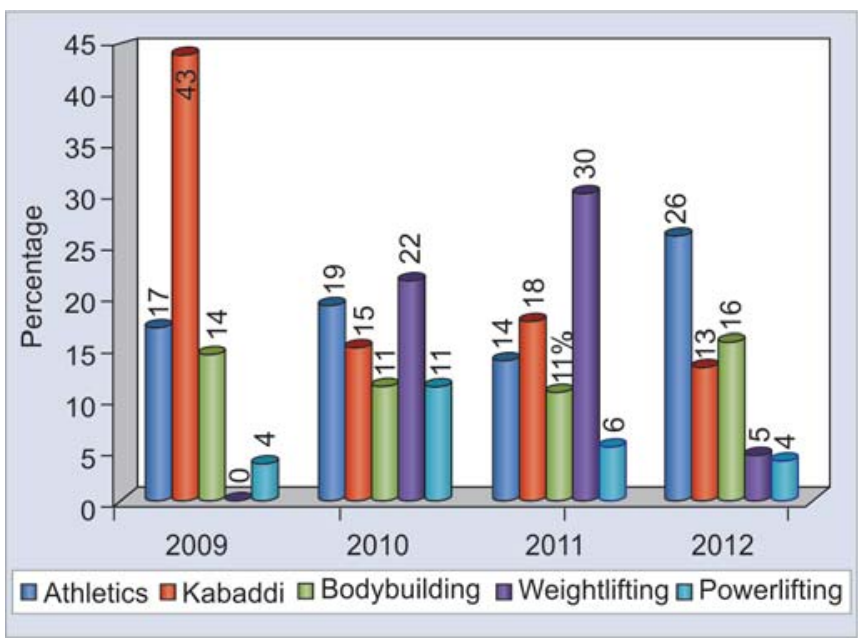

Fig. 1: Details of percentage of positive discipline wise in NDTL, India

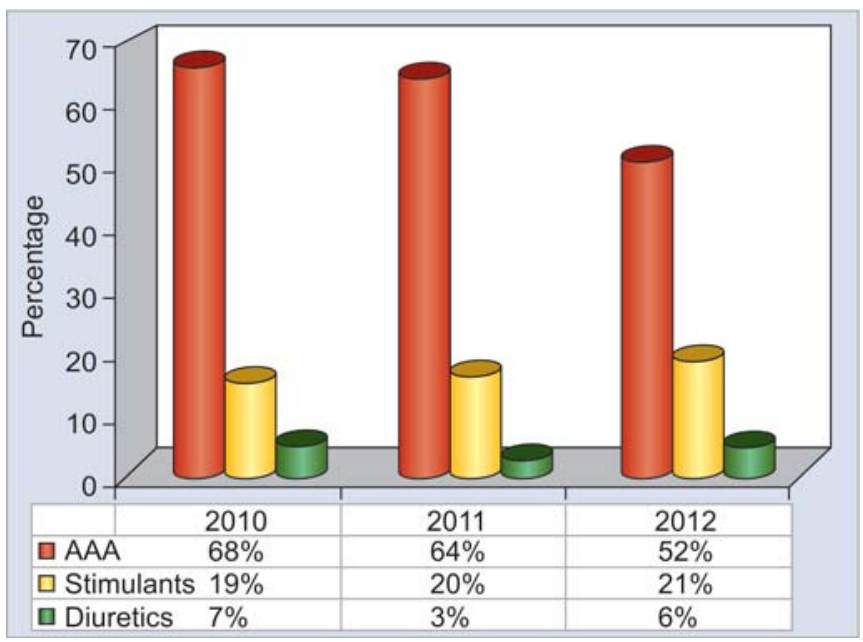

Fig. 2: Details of group-wise percentage of positive in NDTL, India various drugs. The research work on stanozolol, prednisolone and methylprednisolone metabolism helped in identifying three, seven and 10 metabolites of these drugs respectively. ${ }^{9,16,17}$

The athletes need to be aware of the antidoping regulations and changes in the guidelines of the testing/ inclusion of new drugs in the prohibited list. The ignorance about the inclusion of methylhexaneamine in the prohibited list in 2010 led to a sudden emergence of methylhexaneamine positives in India and other parts of the world. ${ }^{6,7,18}$ The increase in the percent positive of methylhexaneamine among stimulants in NDTL, India from 31\% (2010) to 47\% (2011) and 64\% (2012) was comparable to the overall increase in percent positive of the drug by other WADA accredited laboratories as evident from the values of 2010 (21.4\%) and 2011 (39\%) positives reported. ${ }^{14}$ The enantiomeric separation of amphetamine and methamphetamine was also a requirement by WADA to give different sanctions for $\mathrm{D}$ and $\mathrm{L}$ form of the drug. ${ }^{19}$

Apart from having means to detect substances in the urine, ways have been found to detect infusion of blood from another person which has prompted some athletes to infuse themselves with their own blood. ${ }^{20}$ The latest technique, devised to combat this, and other forms of doping, is the biological passport. ${ }^{20}$ This involves frequent testing of athletes to keep track of nine key blood characteristics (biological markers) over a period of time. Any change in athlete's typical biological markers gives indication of foul play which requires further target testing. With methods being in place for the testing of blood doping, more problems loom, and the biggest concern is genetic manipulation. WADA frets that athletes may start improving their bodies by tinkering with their genes.

The testing of amphetamines was a big fear when the race between cheats and their pursuers began with the

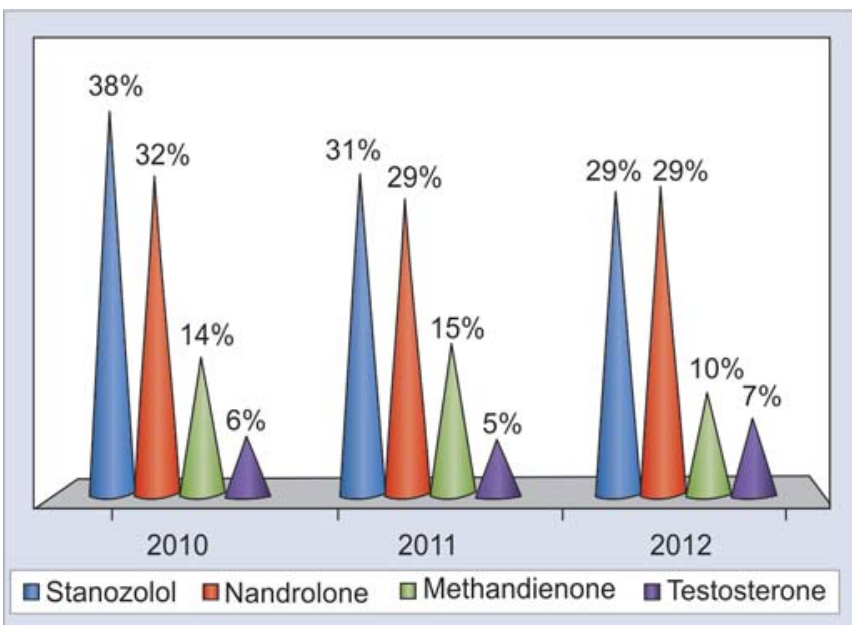

Fig. 3: Details of percentage of positive of most abused anabolic steroids in NDTL, India 
initiation of dope testing during Mexico Olympic Games in 1972. After 40 years, the fear is now of genetic manipulation for performance enhancement which is for sure going to be overcome in view of big budget being spent by WADA on research in devising methods to detect gene doping. The progress in antidoping science in the past 5 decades is immense by which the drug testers may not be ahead of the cheaters but are running neck and neck. It is required from the entire sports fraternity (governments, regulatory agencies, health authorities, educators, athletes and their federations, dope scientists, sports medicine doctors and coaches) to involve in a real joint task and to work as a single team for a common goal of progression in antidoping science for the future benefit of drug-free sport.

\section{ACKNOWLEDGMENT}

The help rendered by Mr Chandan Singh and Mr Jaya Prakash of NDTL, India in statistical evaluation of data is duly acknowledged.

\section{REFERENCES}

1. Beotra A. Drug education handbook on drug abuse in sports (7th ed) 2010;6-9.

2. The World Anti Doping Code. The 2012 prohibited list international standard. Available from: http://www.wadaama.org/rtecontent/document/list_2012.pdf.

3. The World Anti-Doping Code. Technical document on minimum required performance limit. Available from: http://www.wadaama.org/Documents/World_Anti-Doping_Program/WADPISLaboratories/Technical_Documents/WADA_TD2010MRPL v 1.0_Minimum\%20Required\%20Performance\%20Levels_ Sept\%2001\%202010_EN.pdf.

4. Beotra A, Seth SD. Drugs of abuse in sports. Textbook of pharmacology (3rd ed). Elsevier Publication 2009;15:84-90.

5. Ahi S, Beotra A, Upadhyay A, Jain N, Singh R, Jain S. Excretion profile of inhaled formoterol: Distinguishing between therapeutic use and abuse. Proceedings of the 30th Manfred Donike Workshop, Cologne, Germany 2012;20:237-40.

6. Dubey S, Kaur T, Ahi S, Beotra A, Jain S. Strategy for identification and confirmation of 4-methyl-2-hexamine in human urine in doping control. Proceedings of the 29th Manfred Donike Workshop, Cologne, Germany, Recent Advances in Doping Analysis 2011;19:162-65.

7. Kaur T, Dubey S, Ahi S, Beotra A, Jain S. Methylhexaneamine reemergence: From therapeutic use to abuse in sports. ICSEMIS 2012 July 19-24, PSA 30.06, Pg 110.

8. Hans G, Maria KP, Karsten K, Ute M, Wilhelm S, Mario T. Nutritional supplements cross-contaminated and faked with doping substances. J Mass Spectrom 2008;43(7):892-902.
9. Beotra A, Ahi S, Dubey S, Gupta YK, Upadhyay A, Yadav R, et al. Identification of prednisolone, methylprednisolone and their metabolites in human urine using HPLC(+) ESI-MS/MS and detection of possible adulteration in Indian herbal drug preparation. Ibnosina J Med Biomed Sci 2012;4(2):44-52.

10. Beotra A, Shobha A. Synthetic glucocorticosteroids in Indian herbal drugs and supplements. J Traumatol Sports Sci 2011;4-7.

11. Beotra A, Gupta YK, Ahi S, Dubey S, Upadhyay A, Priyadarshi R, et al. Preliminary studies on detection of corticosteroids in adulterated herbal drugs. Proceedings of the 28th Manfred Donike Workshop, Cologne, Germany, Recent Advances in Doping Analysis 2010;18:208-11.

12. Jain S, Beotra A, Kaur T, Lal R, Ahi S, Dubey S, et al. An overview of doping control analysis during Commonwealth Games 2010, New Delhi. Proceedings of the 29th Manfred Donike Workshop, Cologne, Germany, Recent Advances in Doping Analysis 2012;19:124-29.

13. Beotra A, Jain S, Kaur T, Lal R, Ahi S, Dubey S, et al. Doping control analysis during 1st Singapore Youth Olympic Games at NDTL, India. Proceedings of the 29th Manfred Donike Workshop, Cologne, Germany, Recent Advances in Doping Analysis 2011;19:43-47.

14. The World Anti Doping Agency Laboratory Statistics. Available from: http://www.wada-ama.org/en/Anti-Doping-Community/ Anti-DopingLaboratories/Laboratory-Statistics/.

15. Ahi S, Reddy IM, Beotra A, Lal R, Jain S, Kaur T. Sample purification procedure for confirmation of 3-hydroxy stanozolol by gas chromatography/high resolution mass spectrometry. Indian J Pharmacol 2008;40:164-69.

16. Ahi S, Beotra A, Jain S. Detection of mono-hydroxylated metabolites of stanozolol by HPLC-ESI(+) MS/MS in Indian sports persons. Drug Test Anal 2010;1:11-12, 538-54.

17. Beotra A, Ahi S, Upadhyay A, Jain S. Simultaneous identification of prednisolone and its ten metabolites in human urine by high performance liquid chromatography tandem mass spectrometry. Drug Testing Anal 2012;4(6):460-67.

18. Lisi A, Hasick N, Kazlauskas R, Goebel C. Studies of methylhexaneamine in supplements and geranium oil. Drug Test Anal 2011;3(11-12):873-76.

19. Kaur T, Dubey S, Chakraborty M, Jain S, Beotra A. Enantiomeric profiling of amphetamine and methamphetamine in sports person: A comparison of two chiral derivatisation methods. Proceedings of the 28th Manfred Donike Workshop, Cologne, Germany, Recent Advances in Doping Analysis 2010;18:126-29.

20. Kashif M, Beotra A, Joshi M, Donati F, Nair SC, Jain S. Homologous blood transfusion testing in NDTL, India: A case study. Proceedings of the 29th Manfred Donike Workshop, Cologne, Germany, Recent Advances in Doping Analysis 2011; 19:278-83.

\section{ABOUT THE AUTHOR}

\section{Alka Beotra}

Scientific Director, Ministry of Youth Affairs and Sports, New Delhi National Dope Testing Laboratory, India, e-mail: drabeotra@gmail.com 